\title{
Insulin-treated diabetes is not associated with increased mortality in critically ill patients
}

\author{
Jean-Louis Vincent ${ }^{1 *}$, Jean-Charles Preiser ${ }^{2}$, Charles L Sprung ${ }^{3}$, Rui Moreno ${ }^{4}$, Yasser Sakr ${ }^{5}$
}

\begin{abstract}
Introduction: This was a planned substudy from the European observational Sepsis Occurrence in Acutely ill Patients (SOAP) study to investigate the possible impact of insulin-treated diabetes on morbidity and mortality in ICU patients.

Methods: The SOAP study was a cohort, multicenter, observational study which included data from all adult patients admitted to one of 198 participating ICUs from 24 European countries during the study period. For this substudy, patients were classified according to whether or not they had a known diagnosis of insulin-treated diabetes mellitus. Outcome measures included the degree of organ dysfunction/failure as assessed by the sequential organ failure assessment (SOFA) score, the occurrence of sepsis syndromes and organ failure in the ICU, hospital and ICU length of stay, and all cause hospital and ICU mortality.

Results: Of the 3147 patients included in the SOAP study, 226 (7.2\%) had previously diagnosed insulin-treated diabetes mellitus. On admission, patients with insulin-treated diabetes were older, sicker, as reflected by higher simplified acute physiology system II (SAPS II) and SOFA scores, and more likely to be receiving hemodialysis than the other patients. During the ICU stay, more patients with insulin-treated diabetes required renal replacement therapy (hemodialysis or hemofiltration) than other patients. There were no significant differences in ICU or hospital lengths of stay or in ICU or hospital mortality between patients with or without insulin-treated diabetes. Using a Cox proportional hazards regression analysis with hospital mortality censored at 28-days as the dependent factor, insulin-treated diabetes was not an independent predictor of mortality.

Conclusions: Even though patients with a history of insulin-treated diabetes are more severely ill and more likely to have renal failure, insulin-treated diabetes is not associated with increased mortality in ICU patients.
\end{abstract}

\section{Introduction}

Diabetes mellitus is an increasingly common condition, and is estimated to affect approximately 246 million adults worldwide [1]. Although diabetes is occasionally the reason for admission to an intensive care unit (ICU), it is more commonly present as a comorbid condition. Although hyperglycemia can induce a number of immunological alterations [2-5], whether patients with diabetes who are admitted to the ICU are more likely to develop infectious complications remains a controversial issue with studies yielding conflicting results [6-12]. Similarly, some studies $[11,13,14]$, but not all $[10,15]$, have indicated increased mortality in ICU patients with diabetes.

\footnotetext{
* Correspondence: jlvincen@ulb.ac.be

'Department of Intensive Care, Erasme Hospital, Université libre de Bruxelles, route de Lennik 808, 1070 Bruxelles, Belgium
}

In view of the relative lack of data on patients in the ICU with diabetes and the conflicting results from the available data, we investigated the potential impact of insulin-treated diabetes on morbidity and mortality in ICU patients included in a large European epidemiological study, the Sepsis Occurrence in Acutely ill Patients (SOAP) study [16].

\section{Materials and methods}

The SOAP study was a prospective, multicenter, observational study designed to evaluate the epidemiology of sepsis, as well as other characteristics, of ICU patients in European countries. Details of recruitment, data collection, and management have been published previously [16]. Briefly, all patients older than 15 years admitted to the 198 participating centers [see the list of participating countries and centers in Additional data file 1] between 1
C Biomed Central

(c) 2010 Vincent et al.; licensee BioMed Central Ltd. This is an open access article distributed under the terms of the Creative Commons Attribution License (http://creativecommons.org/licenses/by/2.0), which permits unrestricted use, distribution, and reproduction in any medium, provided the original work is properly cited. 
and 15 May, 2002, were included, except patients who stayed in the ICU for less than 24 hours for routine postoperative observation. Patients were followed until death, hospital discharge, or for 60 days. Due to the observational nature of the study, institutional review board approval was either waived or expedited in participating institutions and informed consent was not required.

Data were collected prospectively using pre-printed case report forms. Data collection on admission included demographic data and comorbidities, including diabetes requiring insulin administration. Clinical and laboratory data for the simplified acute physiology score (SAPS) II [17] were reported as the worst value within 24 hours after admission. Microbiologic and clinical infections were reported daily as well as the antibiotics administered. A daily evaluation of organ function according to the sequential organ failure assessment (SOFA) score [18], was performed, with the most abnormal value for each of the six organ systems (respiratory, renal, cardiovascular, hepatic, coagulation, and neurological) collected on admission and every 24 hours thereafter. Infection was defined as the presence of a pathogenic microorganism in a sterile milieu (such as blood, abscess fluid, cerebrospinal fluid or ascitic fluid), and/or clinically documented infection, plus the administration of antibiotics. Sepsis was defined according to consensus conference definitions as infection plus two systemic inflammatory response syndrome (SIRS) criteria [19]. Organ failure was defined as a SOFA score above two for the organ in question [20]. Severe sepsis was defined as sepsis with at least one organ failure.

For the purposes of this study, patients were separated into two groups according to whether or not they had a history of insulin-treated diabetes prior to ICU admission. The a priori defined outcome parameters for this analysis included the degree of organ dysfunction/failure as assessed by the SOFA score, the occurrence of sepsis syndromes and organ failure in the ICU, hospital and ICU lengths of stay, and all-cause hospital and ICU mortality.

\section{Statistical methods}

Data were analyzed using SPSS 13.0 for Windows (SPSS Inc., Chicago, IL, USA). Descriptive statistics were computed for all study variables. A Kolmogorov-Smirnov test was used, and histograms and normal-quantile plots were examined to verify the normality of distribution of continuous variables. Discrete variables are expressed as counts (percentage) and continuous variables as means \pm standard deviation or median (25th to 75 th percentiles). For demographic and clinical characteristics of the study groups, differences between groups were assessed using a chi-squared, Fisher's exact test, Student's t-test or Mann-Whitney U test, as appropriate.
We performed a Cox proportional hazards regression analysis to examine whether the presence of diabetes was associated with mortality. To correct for differences in patient characteristics, we simultaneously included age, gender, SAPS II score on admission, co-morbidities, type of admission (medical or surgical), infection on admission, mechanical ventilation on admission, renal replacement therapy on admission (hemofiltration or hemodialysis), renal failure on admission, and creatinine level on admission. Variables were introduced in the model if significantly associated with a higher risk of 28-day in-hospital death on a univariate basis at a $P$ value less than 0.2 . Colinearity between variables was excluded prior to modelling. Extended Cox models were constructed adding interaction terms. The most parsimonious model was fitted and retained as the final model. We tested the assumption of proportionality of hazards and found no evidence of violation. We also tested the qualitative goodness of fit of the model. All statistics were two-tailed and a $P$ less than 0.05 was considered to be statistically significant.

\section{Results}

Of the 3147 patients included in the SOAP study, 226 (7.2\%) had a prior diagnosis of insulin-treated diabetes mellitus. Table 1 presents the characteristics of the study group on admission to the ICU. Patients with a history of insulin-treated diabetes were older (66 (range 55 to 75) versus 64 (49 to 74 ) years, $P<0.01$ ) and more severely ill on admission, as reflected by the higher SAPS II and SOFA scores, than were patients without a history of insulin-treated diabetes. On admission, more patients with a history of insulin-treated diabetes had renal failure and were undergoing hemodialysis than did patients with no history of insulin-treated diabetes. On admission and during the ICU stay, there were no differences in the occurrence of sepsis or septic shock among ICU patients with and those without a history of insulin-treated diabetes (Tables 1 and 2). During the ICU stay, more patients with a history of insulin-treated diabetes developed renal failure and underwent hemodialysis than did those without a history of insulin-treated diabetes (Table 2).

There were no differences in ICU or hospital lengths of stay in patients with or without a history of insulintreated diabetes and ICU and hospital mortality rates were also similar (Table 2). In the Cox regression model, medical admission, higher SAPS II score, older age comorbid liver cirrhosis, and mechanical ventilation on admission, but not a history of insulin-treated diabetes, were associated with an increased risk of death at 28 days (Table 3 and Figure 1).

\section{Discussion}

The present results demonstrate that in this heterogeneous population of critically ill patients in Western 
Table 1 Characteristics of the study group on admission to the intensive care unit in patients with and without a history of insulin-treated diabetes.

\begin{tabular}{|c|c|c|c|}
\hline & $\begin{array}{l}\text { No history of insulin-treated diabetes } \\
\qquad(\mathrm{n}=2921)\end{array}$ & $\begin{array}{l}\text { History of insulin-treated diabetes } \\
\qquad(n=226)\end{array}$ & $P$ value \\
\hline Age, years, median (IQR) & $64(49-74)$ & $66(55-75)$ & $<0.01$ \\
\hline Sex, male n (\%) & $1790(62)$ & $130(58)$ & 0.2 \\
\hline Medical admission, n (\%) & $1301(45)$ & $87(39)$ & 0.08 \\
\hline \multicolumn{4}{|l|}{ Reason for admission } \\
\hline Digestive/liver & $312(11.3)$ & $21(10.1)$ & 0.35 \\
\hline Respiratory & $519(18.8)$ & $41(19.7)$ & 0.71 \\
\hline Cardiovascular & $878(31.8)$ & $71(34.1)$ & 0.49 \\
\hline Hematological & $26(0.9)$ & $1(0.5)$ & 0.99 \\
\hline Neurological & $455(16.5)$ & $30(14.4)$ & 0.5 \\
\hline Renal & $86(3.1)$ & $18(8.7)$ & $<0.01$ \\
\hline Metabolic & $56(2)$ & $15(7.2)$ & $<0.01$ \\
\hline Trauma & $178(6.4)$ & $3(1.4)$ & $<0.01$ \\
\hline \multicolumn{4}{|l|}{ Comorbid conditions } \\
\hline Cancer, n (\%) & $390(13)$ & $25(11)$ & 0.36 \\
\hline Hematological cancer & $67(2.3)$ & $2(0.9)$ & 0.34 \\
\hline COPD & $317(10.9)$ & $23(10.2)$ & 0.82 \\
\hline HIV infection & $24(0.8)$ & $2(0.9)$ & 0.84 \\
\hline Liver cirrhosis & $110(3.8)$ & $11(4.9)$ & 0.37 \\
\hline Heart failure & $259(8.9)$ & $48(21.2)$ & $<0.001$ \\
\hline \multicolumn{4}{|l|}{ Presence of sepsis, n (\%) } \\
\hline Sepsis & $717(25)$ & $60(27)$ & 0.52 \\
\hline Severe sepsis & $503(17)$ & $49(22)$ & 0.10 \\
\hline Septic shock & $227(7.8)$ & $16(7.1)$ & 0.80 \\
\hline Renal failure on admission & $519(17.8)$ & $56(24.8)$ & 0.01 \\
\hline With hemodialysis & $27(0.9)$ & $10(4.4)$ & $<0.001$ \\
\hline Without hemodialysis & $492(16.8)$ & $46(20.4)$ & 0.20 \\
\hline \multicolumn{4}{|l|}{ Interventions, n (\%) } \\
\hline Mechanical ventilation & $1720(59)$ & $130(58)$ & 0.73 \\
\hline Hemofiltration & $65(2)$ & $8(4)$ & 0.24 \\
\hline Hemodialysis & $36(1)$ & $13(6)$ & $<0.001$ \\
\hline Creatinine, mg/dL & $1.42 \pm 1.40$ & $1.93 \pm 1.90$ & $<0.001$ \\
\hline SAPS II, median (IQR) & $34(24-46)$ & $36(26-49)$ & 0.02 \\
\hline SOFA score, median (IQR) & $6(4-9)$ & $8(4-10)$ & $<0.01$ \\
\hline
\end{tabular}

COPD = chronic obstructive pulmonary disease; IQR = interquartile range; SAPS = simplified acute physiology score; SOFA = sequential organ failure assessment.

Europe, patients with a history of insulin-treated diabetes had similar mortality rates to those without, even though patients with a history of insulin-treated diabetes were more severely ill on admission to the ICU and were more likely to have or to develop renal failure and to require hemodialysis than patients with no history of insulin-treated diabetes. Importantly, these results refer to patients who were receiving insulin on admission and do not reflect the effects of insulin treatment during the hospital stay. The development of renal failure in ICU patients is generally associated with an increase in mortality [21,22]; however, this was not the case in our patients, perhaps because in the majority of the patients renal failure was already present on admission, making it a less important prognostic factor than renal failure that develops later during the ICU admission.

Although diabetes is a relatively common comorbidity in critically ill patients - in our study $7 \%$ of patients had a history of insulin-treated diabetes - its effects on outcomes have not been extensively studied. In the literature, there seems to be considerable variation regarding the effect of diabetes on outcomes in different groups of critically ill patients. In an analysis of a database of 15,408 individuals, Slynkova and colleagues [14] reported that patients with a history of diabetes mellitus were three times more likely to develop acute organ failure and had a threefold risk of dying when hospitalized for that organ failure. In patients with community- 
Table 2 Procedures, organ failures, and presence of infection during the ICU stay, and ICU and hospital outcomes in patients with and without a history of insulin-treated diabetes

\begin{tabular}{|c|c|c|c|}
\hline & $\begin{array}{l}\text { No history of insulin-treated diabetes } \\
\qquad(\mathrm{n}=2921)\end{array}$ & $\begin{array}{l}\text { History of insulin-treated diabetes } \\
\qquad(n=226)\end{array}$ & $P$ value \\
\hline \multicolumn{4}{|l|}{ Infection, n (\%) } \\
\hline Before 48 hours & $825(28)$ & $73(32)$ & 0.19 \\
\hline After 48 hours (ICU acquired) & $263(9)$ & $16(7)$ & 0.33 \\
\hline Sepsis, n (\%) & $1088(37)$ & $89(39)$ & 0.52 \\
\hline Severe sepsis, n (\%) & $855(29)$ & $75(33)$ & 0.23 \\
\hline Septic shock, n (\%) & $423(15)$ & $39(17)$ & 0.28 \\
\hline \multicolumn{4}{|l|}{ Procedures, n (\%) } \\
\hline Mechanical ventilation, at least once & $1886(65)$ & $139(62)$ & 0.35 \\
\hline Hemofiltration, at least once & $187(6)$ & $24(11)$ & 0.02 \\
\hline Hemodialysis, at least once & $111(4)$ & $30(13)$ & $<0.001$ \\
\hline \multicolumn{4}{|l|}{ Organ dysfunction (any time), n (\%) } \\
\hline Renal failure & $1015(35)$ & $105(47)$ & $<0.01$ \\
\hline with hemodialysis on admission & $32(1.1)$ & $11(4.9)$ & $<0.001$ \\
\hline without hemodialysis on admission & $983(34)$ & $94(42)$ & 0.02 \\
\hline Respiratory failure & $1202(41)$ & $99(44)$ & 0.44 \\
\hline Coagulation failure & $289(10)$ & $20(9)$ & 0.73 \\
\hline Hepatic failure & $154(5.3)$ & $14(6)$ & 0.54 \\
\hline CNS failure & $782(27)$ & $57(25)$ & 0.64 \\
\hline Cardiovascular failure & $971(33)$ & $81(36)$ & 0.42 \\
\hline \multicolumn{4}{|l|}{ Organ dysfunction (after 48 hours), n (\%) } \\
\hline Renal failure & $248(9)$ & $23(10)$ & 0.38 \\
\hline Respiratory failure & $208(7)$ & $18(8)$ & 0.64 \\
\hline Coagulation failure & $75(3)$ & $6(3)$ & 0.73 \\
\hline Hepatic failure & $51(2)$ & $4(2)$ & 0.98 \\
\hline CNS failure & $76(3)$ & $5(2)$ & 0.72 \\
\hline Cardiovascular failure & $93(3)$ & $10(4)$ & 0.31 \\
\hline ICU LOS, days, median (IQR) & $3(2-7)$ & $3(2-8)$ & 0.49 \\
\hline Hospital stay, days, median (IQR) & $15(7-32)$ & $17(9-35)$ & 0.15 \\
\hline ICU mortality, n (\%) & $540(19)$ & $43(19)$ & 0.86 \\
\hline Hospital mortality, n (\%) & $684(24)$ & $63(28)$ & 0.15 \\
\hline
\end{tabular}

CNS = central nervous system; ICU = intensive care unit; IQR = interquartile range; LOS = length of stay.

acquired pneumonia, diabetes was an independent predictor of mortality in a multivariate analysis in one study [23], but it was not associated with increased mortality in patients with community-acquired bacteremia in another study [24]. In patients with acute myocardial infarction, diabetes has been associated with increased short-term [25] and long-term [26] mortality; however, in trauma patients, Ahmad and colleagues reported that although patients with diabetes had more complications and longer hospital stays, they did not have higher mortality rates than non-diabetic patients [10]. Also in trauma patients, Kao and colleagues reported that diabetes was associated with increased infectious complications but not with increased mortality [27]. Similar findings have been reported in burn patients [9] and in patients with acute heart failure [28]. In patients undergoing hepatic resection, patients with a history of diabetes had higher rates of postoperative renal failure, but diabetes was not an independent risk factor for mortality [29]. In patients with severe sepsis or septic shock enrolled in a large multicenter trial, Stegenga and colleagues recently reported that patients with a history of diabetes had similar 28-day and 90-day mortality rates to the other patients [30]. In the present study, the incidence of infections acquired during the ICU stay was not higher in patients with a history of insulin-treated diabetes; however, this does not exclude the possibility that some specific subgroups (e.g., cardiac surgery) of diabetic patients may more frequently experience postoperative infections as suggested in other studies [11].

Much has been written in recent years about the potential role of hyperglycemia on admission [31] and during the ICU stay [32,33] on outcomes in ICU patients and the need for tight control of glucose 
Table 3 Summary of Cox proportional hazards model analysis with time to hospital death right-censored at 28 days as the dependent factor.

\begin{tabular}{lccccc}
\hline & $\mathbf{B}$ & $\mathbf{S E}$ & $\mathbf{H R}$ & $\mathbf{9 5 \%} \mathbf{C l}$ & $\mathbf{P}$ \\
\hline Medical admission & 0.71 & 0.094 & 2.04 & $1.70-2.45$ & $<0.001$ \\
Age, year & 0.01 & 0.003 & 1.01 & $1.00-1.02$ & 0.001 \\
SAPS II score (per point) & 0.04 & 0.002 & 1.05 & $1.04-1.05$ & $<0.001$ \\
$\begin{array}{l}\text { Mechanical ventilation, on } \\
\text { admission }\end{array}$ & 0.30 & 0.111 & 1.35 & $1.09-1.68$ & 0.007 \\
$\begin{array}{l}\text { Liver cirrhosis on } \\
\text { admission }\end{array}$ & 0.79 & 0.160 & 2.19 & $1.60-3.00$ & $<0.001$ \\
Insulin-treated diabetes & -0.24 & 0.157 & 0.78 & $0.58-1.07$ & 0.120
\end{tabular}

$\mathrm{B}=$ coefficient estimate; $\mathrm{Cl}=$ confidence interval; $\mathrm{HR}=$ hazard ratio; SAPS = simplified acute physiology score; $\mathrm{SE}=$ standard error of the estimate. concentrations using insulin [34-38]. Hyperglycemia has been associated with impaired neutrophil chemotaxis, oxidative burst, and phagocytosis and increased neutrophil adherence [2-5]. Using intravital microscopy, Booth and colleagues demonstrated that hyperglycemia was able to initiate an inflammatory response in the microcirculation [39], and correction of hyperglycemia in critically ill patients has been associated with improved outcomes $[34,40]$. Our present study was not focused on hyperglycemia. Whether or not blood glucose should be strictly controlled is a different issue, which requires prospective, controlled, randomized studies as in the study by Van den Berghe and colleagues in which surgical ICU patients who were managed with a strict protocol to maintain blood glucose concentrations between 80 and $110 \mathrm{mg} / \mathrm{dl}(4.4$ and $6.1 \mathrm{mmol} / \mathrm{l})$ had less

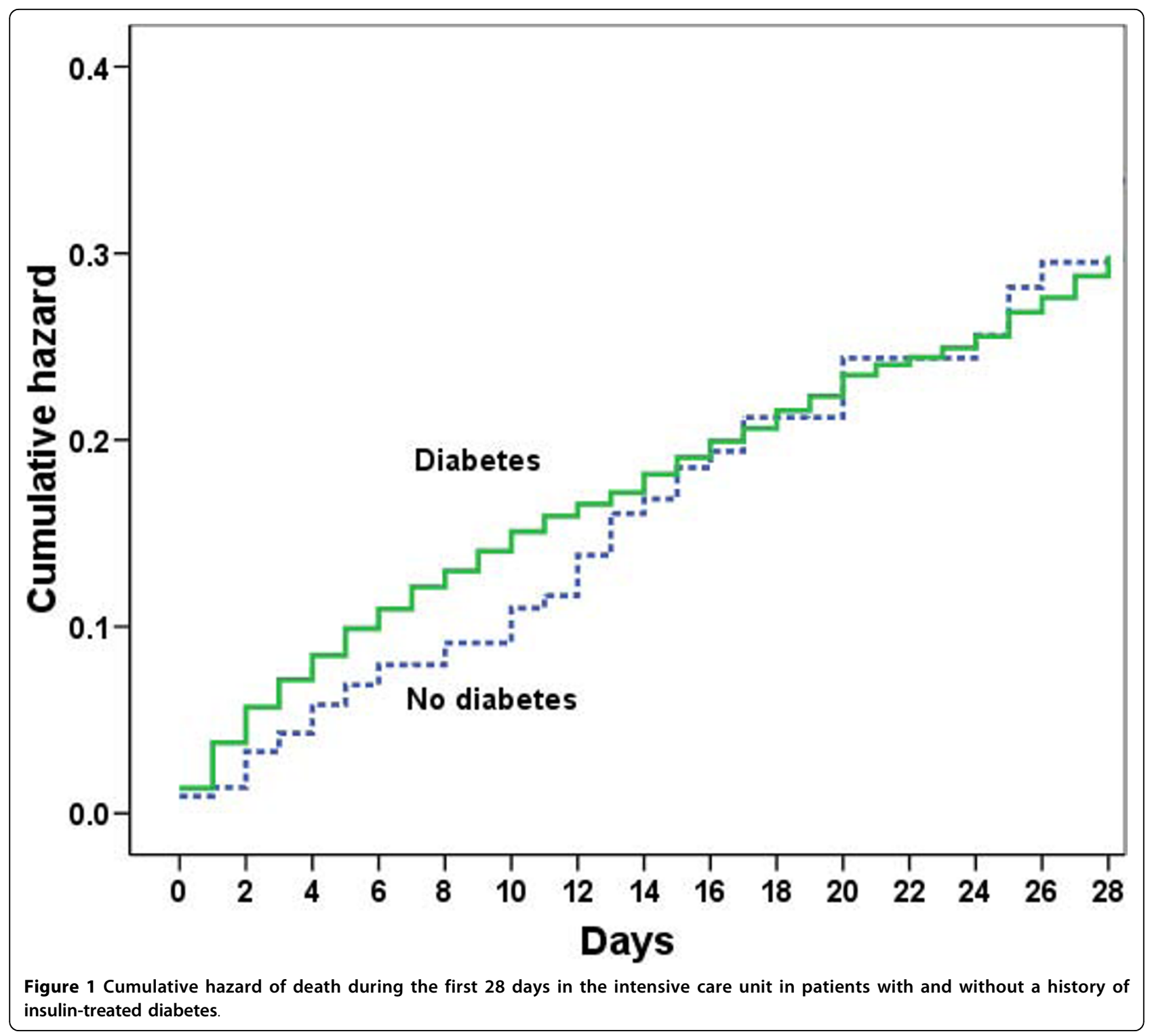


morbidity and lower mortality than patients treated conventionally [34]. This approach is still very controversial [35]. Interestingly, in these studies by Van den Berghe and colleagues $[34,40]$, patients who had a history of diabetes did not benefit from the tight glucose control approach [36]. Several other studies have also indicated that, although many ICU patients with newly diagnosed or stress hyperglycemia have worse outcomes than normoglycemic patients, this relation does not hold true or is less marked for patients with known diabetes [41-46]. In the recent SAPS III study, diabetes, with or without insulin treatment, was associated with a worse hospital mortality in multivariate analysis [47]. Interestingly, diabetic patients with septic shock may have a lower incidence of developing acute lung injury or acute respiratory distress syndrome[48,49].

The present study has some limitations including that, as part of an observational study with a waiver of informed consent, we were unable to obtain glycosylated hemoglobin measurements and also did not have blood glucose levels to evaluate the degree of control of the diabetes before or during the ICU admission. In addition, we compared patients with a history of insulintreated diabetes to a cohort consisting of non-diabetics and non-insulin-treated diabetics, and have no data on the numbers of non-insulin-treated diabetics in this cohort. More importantly, we did not separate patients with type 1 and type 2 diabetes because this information is difficult to define in ICU patients. The slightly higher proportion of medical patients in the non-diabetic group could represent a confounding factor, because mortality is usually higher in medical than in surgical ICU patients. Finally, we evaluated a heterogeneous patient population but the multivariate analysis we performed adjusted for a large number of variables, which are known to influence outcome prediction.

\section{Conclusions}

In conclusion, in this general ICU population, although patients with a history of insulin-treated diabetes were more severely ill and more likely to have renal failure, insulin-treated diabetes was not associated with increased ICU or hospital mortality rates.

\section{Key messages}

- Patients with a history of insulin-treated diabetes are more severely ill on admission to the ICU and more likely to have or develop renal failure and to require hemodialysis than patients with no history of insulin-treated diabetes.

- However, ICU and hospital mortality rates were similar in patients with and without a history of insulin-treated diabetes.
Additional file 1: SOAP participants. A word file listing the participants in the Sepsis Occurrence in Acutely III Patients (SOAP) study in alphabetical order

Click here for file

[http://www.biomedcentral.com/content/supplementary/cc8866-S1.doc ]

\section{Abbreviations}

ICU: intensive care unit; SAPS: simplified acute physiology score; SIRS: systemic inflammatory response syndrome; SOAP: sepsis in acutely ill patients; SOFA: sequential organ failure assessment.

\section{Acknowledgements}

The SOAP study was supported by an unlimited grant from Abbott, Baxter, Eli Lilly, GlaxoSmithKline, and NovoNordisk. These companies had no involvement at any stage of the study design, in the collection and analysis of data, in writing the manuscript, or in the decision to submit for publication.

\section{Author details}

'Department of Intensive Care, Erasme Hospital, Université libre de Bruxelles, route de Lennik 808, 1070 Bruxelles, Belgium. ²Department of General Intensive Care, University Hospital Centre of Liege, Domaine Universitaire du Sart Tilman B 35, 4000 Liege, Belgium. ${ }^{3}$ Department of Anesthesiology and Critical Care Medicine, Hadassah Hebrew University Medical Center, P.O.B. 12000, 91120 Jerusalem, Israel. ${ }^{4}$ Department of Intensive Care, Hospital de St Antonio dos Capuchos, Alameda de Santo António dos Capuchos, 1169-050 Lisbon, Portugal. ${ }^{5}$ Department of Anesthesiology and Intensive Care, Friedrich-Schiller-University, Erlanger Allee 101, Jena 07743, Germany.

\section{Authors' contributions}

JLV conceived the initial SOAP study. JCP, CLS, RM, YS, and JLV participated in the design and coordination of the SOAP study. YS performed the statistical analyses. YS and JLV drafted the present manuscript. All authors read and approved the final manuscript.

\section{Competing interests}

The authors declare that they have no competing interests.

Received: 14 September 2009 Revised: 21 December 2009

Accepted: 4 February 2010 Published: 4 February 2010

\section{References}

1. International Diabetes Federation: Diabetes Atlas. Brussels: International Diabetes Federation, 32006.

2. Nielson CP, Hindson DA: Inhibition of polymorphonuclear leukocyte respiratory burst by elevated glucose concentrations in vitro. Diabetes 1989, 38:1031-1035.

3. Alexiewicz JM, Kumar D, Smogorzewski M, Klin M, Massry SG: Polymorphonuclear leukocytes in non-insulin-dependent diabetes mellitus: abnormalities in metabolism and function. Ann Intern Med 1995, 123:919-924.

4. Kjersem H, Hilsted J, Madsbad S, Wandall JH, Johansen KS, Borregaard N: Polymorphonuclear leucocyte dysfunction during short term metabolic changes from normo- to hyperglycemia in type 1 (insulin dependent) diabetic patients. Infection 1988, 16:215-221.

5. Rassias AJ, Givan AL, Marrin CA, Whalen K, Pahl J, Yeager MP: Insulin increases neutrophil count and phagocytic capacity after cardiac surgery. Anesth Analg 2002, 94:1113-1119, table.

6. Sreeramoju PV, Tolentino J, Garcia-Houchins S, Weber SG: Predictive factors for the development of central line-associated bloodstream infection due to gram-negative bacteria in intensive care unit patients after surgery. Infect Control Hosp Epidemiol 2008, 29:51-56.

7. Bochicchio GV, Joshi M, Bochicchio K, Shih D, Meyer W, Scalea TM: Incidence and impact of risk factors in critically ill trauma patients. World J Surg 2006, 30:114-118.

8. Bucerius J, Gummert JF, Walther T, Doll N, Falk V, Onnasch JF, Barten MJ, Mohr FW: Impact of diabetes mellitus on cardiac surgery outcome. Thorac Cardiovasc Surg 2003, 51:11-16. 
9. McCampbell B, Wasif N, Rabbitts A, Staiano-Coico L, Yurt RW, Schwartz S: Diabetes and burns: retrospective cohort study. J Burn Care Rehabil 2002, 23:157-166.

10. Ahmad R, Cherry RA, Lendel I, Mauger DT, Service SL, Texter LJ, Gabbay RA: Increased hospital morbidity among trauma patients with diabetes mellitus compared with age- and injury severity score-matched control subjects. Arch Surg 2007, 142:613-618.

11. Brown JR, Edwards FH, O'Connor GT, Ross CS, Furnary AP: The diabetic disadvantage: historical outcomes measures in diabetic patients undergoing cardiac surgery - the pre-intravenous insulin era. Semin Thorac Cardiovasc Surg 2006, 18:281-288.

12. Vardakas KZ, Siempos II, Falagas ME: Diabetes mellitus as a risk factor for nosocomial pneumonia and associated mortality. Diabet Med 2007, 24:1168-1171.

13. Pittet D, Thiévent B, Wenzel RP, Li N, Gurman G, Suter PM: Importance of pre-existing co-morbidities for prognosis of septicemia in critically ill patients. Intensive Care Med 1993, 19:265-272.

14. Slynkova K, Mannino DM, Martin GS, Morehead RS, Doherty DE: The role of body mass index and diabetes in the development of acute organ failure and subsequent mortality in an observational cohort. Crit Care 2006, 10:R137.

15. Ligtenberg JJ, Meijering S, Stienstra $Y$, van $d H$ I, Vogelzang M, Nijsten MW Tulleken JE, Zijlstra JG: Mean glucose level is not an independent risk factor for mortality in mixed ICU patients. Intensive Care Med 2006, 32:435-438.

16. Vincent $J$, Sakr Y, Sprung CL, Ranieri VM, Reinhart K, Gerlach H, Moreno R, Carlet J, Le Gall JR, Payen D: Sepsis in European intensive care units: results of the SOAP study. Crit Care Med 2006, 34:344-353.

17. Le Gall J-R, Lemeshow S, Saulnier F: A new simplified acute physiology score (SAPS II) based on a European/North American multicenter study. JAMA 1993, 270:2957-2963.

18. Vincent JL, Moreno R, Takala J, Willatts S, de Mendonça A, Bruining H, Reinhart CK, Suter PM, Thijs LG: The SOFA (Sepsis-related Organ Failure Assessment) score to describe organ dysfunction/failure. Intensive Care Med 1996, 22:707-710.

19. American College of Chest Physicians/Society of Critical Care Medicine Consensus Conference: definitions for sepsis and organ failure and guidelines for the use of innovative therapies in sepsis. Crit Care Med 1992, 20:864-874.

20. Vincent $J L$, de Mendonça A, Cantraine F, Moreno R, Takala J, Suter P, Sprung C, Colardyn FC, Blecher S: Use of the SOFA score to assess the incidence of organ dysfunction/failure in intensive care units: Results of a multicentric, prospective study. Crit Care Med 1998, 26:1793-1800.

21. Guerin C, Girard R, Selli JM, Perdrix JP, Ayzac L: Initial versus delayed acute renal failure in the intensive care unit. A multicenter prospective epidemiological study. Rhone-Alpes Area Study Group on Acute Renal Failure. Am J Respir Crit Care Med 2000, 161:872-879.

22. Uchino S, Kellum JA, Bellomo R, Doig GS, Morimatsu H, Morgera S, Schetz M, Tan I, Bouman C, Macedo E, Gibney N, Tolwani A, Ronco C: Acute renal failure in critically ill patients: a multinational, multicenter study. JAMA 2005, 294:813-818.

23. Falguera M, Pifarre R, Martin A, Sheikh A, Moreno A: Etiology and outcome of community-acquired pneumonia in patients with diabetes mellitus. Chest 2005, 128:3233-3239.

24. Tsai CL, Lee CC, Ma MH, Fang CC, Chen SY, Chen WJ, Chang SC, Mehta SH: Impact of diabetes on mortality among patients with communityacquired bacteremia. J Infect 2007, 55:27-33.

25. Kvan E, Pettersen Kl, Sandvik L, Reikvam A: High mortality in diabetic patients with acute myocardial infarction: cardiovascular co-morbidities contribute most to the high risk. Int J Cardiol 2007, 121:184-188,

26. Ishihara M, Kagawa E, Inoue I, Kawagoe T, Shimatani $Y$, Kurisu S, Nakama $Y$, Maruhashi T, Ookawa K, Dai K, Aokage Y: Impact of admission hyperglycemia and diabetes mellitus on short- and long-term mortality after acute myocardial infarction in the coronary intervention era. Am J Cardiol 2007, 99:1674-1679.

27. Kao LS, Todd SR, Moore FA: The impact of diabetes on outcome in traumatically injured patients: an analysis of the National Trauma Data Bank. Am J Surg 2006, 192:710-714.

28. Greenberg BH, Abraham WT, Albert NM, Chiswell K, Clare R, Stough WG, Gheorghiade M, O'Connor CM, Sun JL, Yancy CW, Young JB, Fonarow GC: Influence of diabetes on characteristics and outcomes in patients hospitalized with heart failure: a report from the Organized Program to Initiate Lifesaving Treatment in Hospitalized Patients with Heart Failure (OPTIMIZE-HF). Am Heart J 2007, 154:277-278.

29. Guckelberger O, Thelen A, Benckert C, Schoebel C, Reuter S, Klupp J, Jonas $S$, Neuhaus P: Diabetes mellitus is no independent risk factor for perioperative mortality following hepatic resection. Exp Clin Endocrinol Diabetes 2006, 114:257-261.

30. Stegenga ME, Vincent JL, Vail GM, Williams MD, Bernard GR, Poll Van der T: Diabetes does not alter mortality or hemostatic and inflammatory responses in patients with severe sepsis [abstract]. Crit Care Med 2010, 38:539-545.

31. Umpierrez GE, Isaacs SD, Bazargan N, You X, Thaler LM, Kitabchi AE: Hyperglycemia: an independent marker of in-hospital mortality in patients with undiagnosed diabetes. J Clin Endocrinol Metab 2002, 87:978-982.

32. Finney SJ, Zekveld C, Elia A, Evans TW: Glucose control and mortality in critically ill patients. JAMA 2003, 290:2041-2047.

33. Krinsley JS: Effect of an intensive glucose management protocol on the mortality of critically ill adult patients. Mayo Clin Proc 2004, 79:992-1000.

34. Berghe Van den $G$, Wouters $P$, Weekers F, Verwaest $C$, Bruyninckx F, Schetz M, Vlasselaers D, Ferdinande P, Lauwers P, Bouillon R: Intensive insulin therapy in the critically ill patient. N Engl J Med 2001, 345:1359-1367.

35. Merz TM, Finfer S: Pro/con debate: Is intensive insulin therapy targeting tight blood glucose control of benefit in critically ill patients?. Crit Care 2008, 12:212.

36. Berghe Van den G, Wilmer A, Milants I, Wouters PJ, Bouckaert B, Bruyninckx F, Bouillon R, Schetz M: Intensive insulin therapy in mixed medical/surgical intensive care units: benefit versus harm. Diabetes 2006, 55:3151-3159.

37. Devos P, Preiser JC: Is it time for implementation of tight glycaemia control by intensive insulin therapy in every ICU?. Crit Care 2006, 10:130

38. Preiser JC, Devos P: Clinical experience with tight glucose control by intensive insulin therapy. Crit Care Med 2007, 35:S503-S507.

39. Booth G, Stalker TJ, Lefer AM, Scalia R: Elevated ambient glucose induces acute inflammatory events in the microvasculature: effects of insulin. Am J Physiol Endocrinol Metab 2001, 280:E848-E856.

40. Berghe Van den G, Wilmer A, Hermans G, Meersseman W, Wouters PJ, Milants I, Van Wijngaerden E, Bobbaers $H$, Bouillon R: Intensive insulin therapy in the medical ICU. N Engl J Med 2006, 354:449-461.

41. Rady MY, Johnson DJ, Patel BM, Larson JS, Helmers RA: Influence of individual characteristics on outcome of glycemic control in intensive care unit patients with or without diabetes mellitus. Mayo Clin Proc 2005, 80:1558-1567.

42. Whitcomb BW, Pradhan EK, Pittas AG, Roghmann MC, Perencevich EN: Impact of admission hyperglycemia on hospital mortality in various intensive care unit populations. Crit Care Med 2005, 33:2772-2777.

43. Krinsley JS: Glycemic control, diabetic status, and mortality in a heterogeneous population of critically ill patients before and during the era of intensive glycemic management: six and one-half years experience at a university-affiliated community hospital. Semin Thorac Cardiovasc Surg 2006, 18:317-325.

44. Stead LG, Gilmore RM, Bellolio MF, Mishra S, Bhagra A, Vaidyanathan L, Decker WW, Brown RD Jr: Hyperglycemia as an independent predictor of worse outcome in non-diabetic patients presenting with acute ischemic stroke. Neurocrit Care 2009, 10(2):181-186.

45. Sleiman I, Morandi A, Sabatini T, Ranhoff A, Ricci A, Rozzini R, Trabucchi M: Hyperglycemia as a predictor of in-hospital mortality in elderly patients without diabetes mellitus Admitted to a Sub-Intensive Care Unit. J Am Geriatr Soc 2008, 56:1106-1110.

46. Egi M, Bellomo R, Stachowski E, French CJ, Hart GK, Hegarty C, Bailey M: Blood glucose concentration and outcome of critical illness: the impact of diabetes. Crit Care Med 2008, 36:2249-2255.

47. Moreno RP, Metnitz PG, Almeida E, Jordan B, Bauer P, Campos RA, lapichino G, Edbrooke D, Capuzzo M, Le Gall JR: SAPS 3-From evaluation of the patient to evaluation of the intensive care unit. Part 2: Development of a prognostic model for hospital mortality at ICU admission. Intensive Care Med 2005, 31:1345-1355.

48. Moss M, Guidot DM, Steinberg KP, Duhon GF, Treece P, Wolken R, Hudson LD, Parsons PE: Diabetic patients have a decreased incidence of acute respiratory distress syndrome. Crit Care Med 2000, 28:2187-2192. 
49. Iscimen R, Cartin-Ceba R, Yilmaz M, Khan H, Hubmayr RD, Afessa B, Gajic O: Risk factors for the development of acute lung injury in patients with septic shock: an observational cohort study. Crit Care Med 2008, 36:1518-1522.

\section{doi:10.1186/cc8866}

Cite this article as: Vincent et al:: Insulin-treated diabetes is not associated with increased mortality in critically ill patients. Critical Care 2010 14:R12.

Submit your next manuscript to BioMed Central and take full advantage of:

- Convenient online submission

- Thorough peer review

- No space constraints or color figure charges

- Immediate publication on acceptance

- Inclusion in PubMed, CAS, Scopus and Google Scholar

- Research which is freely available for redistribution 